IRA-International Journal of Management \&

Social Sciences

ISSN 2455-2267; Vol.15, Issue 03 (June, 2019)

Pg. no. 48-64.

Institute of Research Advances

http://research-advances.org/index.php/RAJMSS

\title{
Understanding Substance Abuse and its Correlation with Social Changes in Sikkim: A Sociological Study
}

Peter Rai

Middle Gelling, Jorethatng Chakung, Sikkim, India.

Type of Work: Peer Reviewed.

DOl: http://dx.doi.org/10.21013/jmss.v15.n3.p1

How to cite this paper:

Rai, P. (2019). Understanding Substance Abuse and its Correlation with Social Changes in Sikkim: A Sociological Study. IRA-International Journal of Management \& Social Sciences (ISSN 2455-2267), 15(3), 48-64. doi:http://dx.doi.org/10.21013/jmss.v15.n3.p1

\section{(C) Institute of Research Advances.}

\section{(cc)) BY-NC}

This work is licensed under a Creative Commons Attribution-Non Commercial 4.0 International License subject to a proper citation to the publication source of the work.

Disclaimer: The scholarly papers as reviewed and published by the Institute of Research Advances (IRA) are the views and opinions of their respective authors and are not the views or opinions of the IRA. The IRA disclaims of any harm or loss caused due to the published content to any party.

Institute of Research Advances is an institutional publisher member of Publishers International Linking Association Inc. (PILA-CrossRef), USA. The institute is an institutional signatory to the Budapest Open Access Initiative. Hungary advocating the open access of scientific and scholarly knowledge. The Institute is a registered content provider under Open Access Initiative Protocol for Metadata Harvesting (OAl-PMH).

The journal is indexed \& included in WorldCat Discovery Service (USA), CrossRef Metadata Search (USA), WorldCat (USA), OCLC (USA), Open J-Gate (India), EZB (Germany) Scilit (Switzerland), Airiti (China), Bielefeld Academic Search Engine (BASE) of Bielefeld University, Germany, PKP Index of Simon Fraser University, Canada. 


\section{Introduction:}

In contemporary society, the full-fledged impact of modernisation and globalisation which has given the free movement of people, goods and money across the countries of the world can be witnessed. This has also opened the economic opportunities among the individuals and communities in the society, which has become a new way of life. Society has changed over the years and activities of the people have also undergone social change. Even the trend of taking drugs has changed with change in society. Traditionally used drugs have been replaced by modern synthetic drugs. The proliferation of pharmaceutical industries, which manufactures narcotic drugs, has, directly and indirectly, encouraged the use and abuse of drugs due to easy access in the market. The epidemic of illicit drug users in the global society has increased significantly and simultaneously related crimes in society.

Drug abuse is global phenomena. A drug is a biological substance, synthetic or natural, which is taken primarily for non-dietary needs, and it is a substance, which affects the functioning of the mind and body or both. ${ }^{1}$ Globally, according to UNODC estimate, in 2009 , between 149 and 272 million people, or $3.3 \%$ to $6.1 \%$ of the population aged 15-64, had used illicit substance once in the previous year. Cannabis and ATS (Amphetamine-type stimulants) are two important drugs which are commonly used worldwide. ${ }^{2}$ Within Asia, ATS ranks as the main drug of abuse in Thailand, Japan, Republic of Korea and the Philippines, and also China, Myanmar and Indonesia are in the second rank (UNODC, 2004). ${ }^{3}$ Heroin, cocaine and other drugs kill around 0.2 million people each year and also causes health problems with incurable diseases. ${ }^{4}$ The European Monitoring Centre for Drug and Drug Addiction (EMCDDA) defines the problem of drug use as, "injecting drug use or long duration regular use of opium, cocaine and amphetamines". World Health Organisation (WHO), defines drug addiction as a 'disease,' and the American Psychiatric Association, define drug abuse as the 'illicit consumption of any naturally occurring of pharmaceutical substance for the purpose of changing the way, in which a person feels, thinks or behaves, without understanding or taking into consideration the damaging physical and mental side-effects that are caused. ${ }^{6}$

India is a diverse nation, the largest democracy in the world but has the social problem of drug abuse and drug addiction among the youths in the society. Drugs like opium and cannabis were traditionally used by the people, which were taken as a pain reliever in those societies. Cannabis or 'ganja' was also consumed to worship Hindu Lord Shiva, during the festival of 'Shivratri' ${ }^{7}$ in India. According to a nationwide survey spread over 13 states by an NGO, in collaboration with the Ministry of Women and Child Development found that $32.1 \%$ children, below the age of 18, had tasted bhang, ganja, heroin or other forms of narcotics. ${ }^{8}$ In 2008, 5.3 million Indians age 12 and older had abused cocaine in any form and 1.1 million had abused crack at least once in the year. In 2008, 802,000 Indians aged 12and older had abused LSD at least once in the year. In 2008, 453,000Indians age 12 and older had abused heroin at least once in the year. In 2008, 25.8 million Indians age 12 and older had abused marijuana at least once in the year. In 2008, 850,000 Indians age 12 and older had abused methamphetamine at least once in the year. ${ }^{9}$

Northeast India where there has been a serious problem of drug use and these states are very close to Bangladesh and Myanmar. Nagaland and Manipur are the two states in Northeast India, which has the highest prevalence of Intravenous Drug Users (IDUs). Even, cultivation of opium is done in Manipur, Nagaland and Arunachal Pradesh, and supplied to other parts of India. ${ }^{10}$ There is an easy way for drug trafficking across the common border of Myanmar and the three North-eastern states of India (Manipur, Mizoram and Nagaland). There is

\footnotetext{
${ }^{1}$ P. Mehta; Evaluative Trends of Illicit Drugs uses in India...., pp. 32.

${ }^{2}$ World Drug Report 2010, pp. 123.

${ }^{3}$ See 'changing drug abuse patterns and law enforcement strategies, pp. 134.

${ }^{4}$ World Drug Report 2012, p.iii.

${ }^{5}$ World Drug Report 2010. 'Drug Use and Trends', pp. 125-126.

${ }^{6}$ P. Mehta, 2011; pp. 32.

7 B. Sundas , 2011; pp.50.

${ }^{8}$ P. Mehta 2011; pp. 33.

${ }^{9}$ Ibid, pp. 34-40.

${ }^{10}$ Drug Policy Briefing Nr. 35, 2011; pp. 1-7
} 
illicit cultivation of opium and cannabis, the heroin and amphetamines, and the pharmaceuticals are used as illicit drugs and trafficked in North-east India. ${ }^{11}$

The small state Sikkim is situated at the base of Mount Kanchenjunga and is sparsely populated. Drug abuse is a growing problem of this state and prevalence among the youth is high, due to the availability and easy access.

\section{The conceptualisation of the Study:}

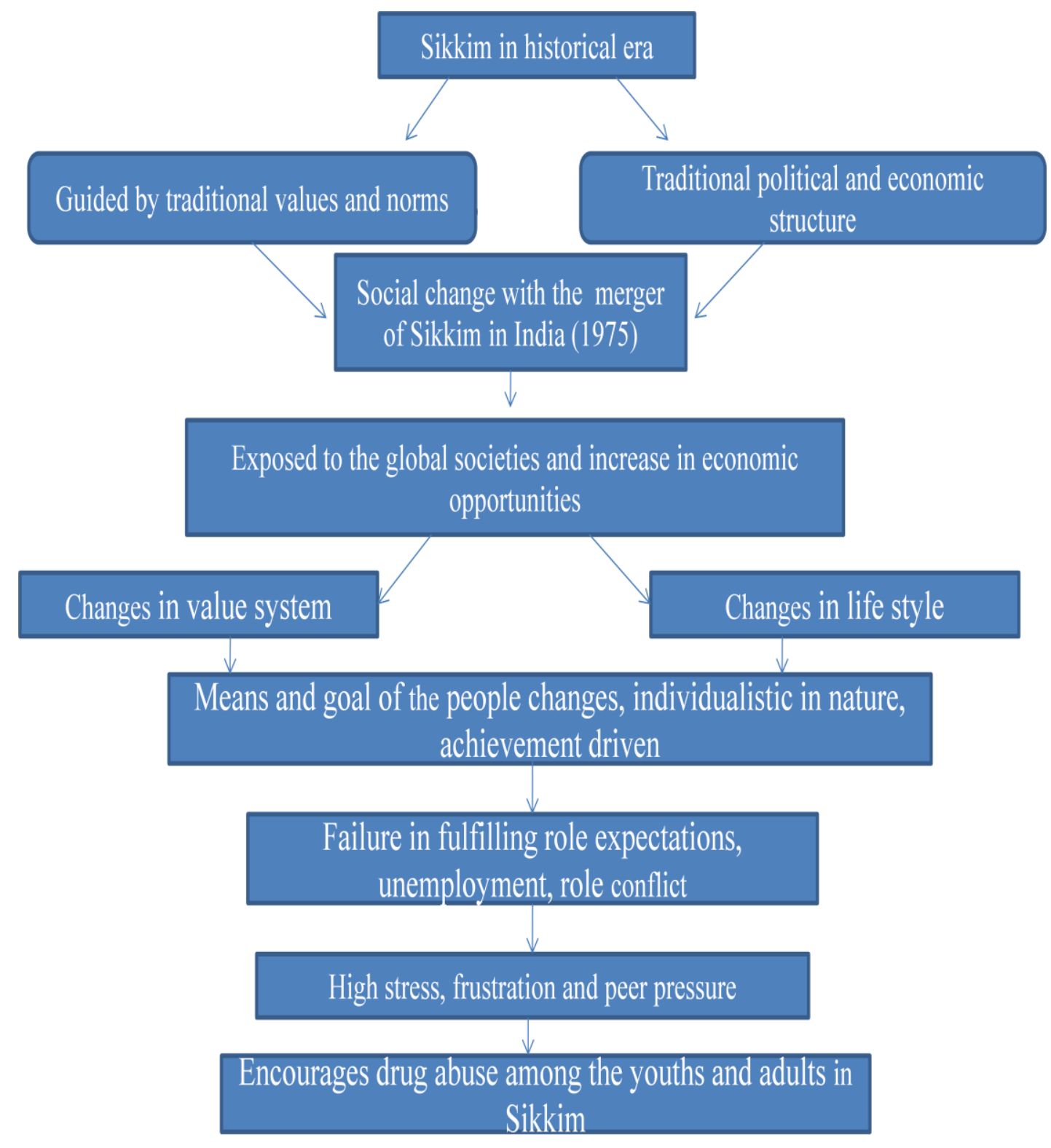

Figure 1: Conceptualisation of the Study

\footnotetext{
${ }^{11}$ Drug Use in Northeastern States of India, pp. xiv.
} 
Sikkim became the $22^{\text {nd }}$ state of India in 1975; under the Thirty-eighth Amendment of the constitution of India $^{12}$ (Das, 2002). Prior to it, the state was recognised as the Protectorate state of India. ${ }^{13}$ Sikkim has a diverse cultural heritage emerging from the three ethnic groups who settled in this region in the pre-historic period. These ethnic groups are the Lepchas, Bhutias and the Nepalis. The Lepchas are considered to be from the hills of Assam, ${ }^{14}$ Bhutias from the Tibet, ${ }^{15}$ the Nepalese from Nepal $;{ }^{16}$ however they build a harmonious social system in the hills. Since, after the British invasion, Sikkim has played a significant role in international trade and commerce among the nations across the state ${ }^{17}$ Geographically it is strategically located for international relations cutting across India, Tibet, China, Nepal and Bhutan. This feature of the state had attracted the British as well as other communities in the region which led to many social and structural changes in the region. There has been a chain of structural changes in Sikkim, from being an independent kingdom it became a protectorate state of India, later it became an integral part of the Union of India. The docile tribes and people living in the state of Sikkim were gradually exposed to the outside world and development in socio-economic infrastructure.

Before the merger with India, the people of Sikkim were mostly illiterate, modern education was very rare in the state and was a privilege of the handful of elite class people and was inaccessible for the poor people. Later on, the political structure changed into a democratic form of government, the society was relieved from the hardships of life under the monarchy and education also spread subsequently. Education brought overall development in man power which is indispensable for the economic growth of the nation as a whole. ${ }^{18}$ Gradually the system of primary education started in Sikkim and started reaching villages and the common people of Sikkim. For higher education, people faced numerous problems which were gradually taken care with the establishment of high schools and colleges.

In the initial period, the economy of the state was very low and there was a pathetic condition in terms of communication system, the kingdom was depended on the revenue or tax collection from the subjects. Traditionally agriculture has been the mainstay of Sikkim's economy from the period of very beginning in Sikkim. ${ }^{19}$ This agrarian economy was based upon traditional ways of cultivation and the production depended on the size of the family, which is known as the institution of socialization in every society. The family was based on the traditional norms and values and had strong bonding among its members and father used to be the patriarch and had complete control over his family. The size of the family used to be big earlier, because they needed physical labour to work in the field or for the division of labour to produce more food grains for their livelihood. The kinship organisations were setup on high values and sentiments, kinsmen were concerned for other kit and kin.

The change in social and economic patters is often associated with the creation of a new type of organisation. The economic changes led to major changes in the other institutions like the family, in terms of structure, kin group and local communities. ${ }^{20}$ The traditional values of the community orients towards the new rational legal system and that transformation took place gradually in the society of Sikkim. The breaking down of families from joint to nuclear family structure largely encouraged the individualism which hampered the social relation of the family and the community at large. Due to the new settlements of the population in the urban areas, where modern legal system guided the individual behaviours, the intimacy between the parents and kin deteriorated and youngsters were more engaged with peer groups and leisure groups.

Gradually transportation and communication system developed in the state of Sikkim which helped people to move from one place to another efficiently. 'In 1906, for the first time, Gangtok was linked with India by

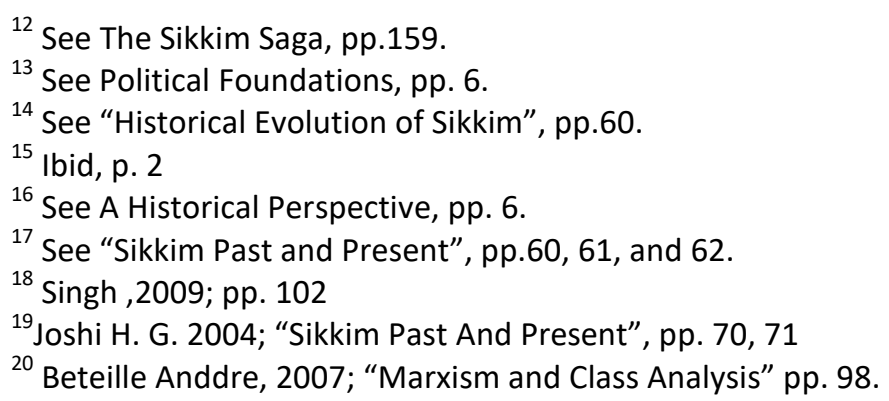


wheeled traffic'. ${ }^{21}$ Since then, there have been drastic changes taking place in the various institutions and organizations in Sikkim, with the help of many modern technologies. The state of Sikkim also became a hub of tourism which led to the opening of many skilled and unskilled jobs due to development. Simultaneously the frequency of deviance in the society also increased and is a cause of concern for the society. The contemporary society of Sikkim has been witness to varieties of structural changes which run parallel to the progress and development of the society and the individual in the society. 'Each social problem is the product of existing social institution'. ${ }^{22}$ When a society transforms from traditional to modern there is maximum chance of cultural lag occurring due to the fragmentation in ideas, of peoples belonging to different-generation with regards to cultural beliefs and folk practices, through oral traditions ${ }^{23}$ not followed by the younger one. There were continuous growth and engagement of modern sophistication and contiguous entertainment space which led people to under look the traditional norms and values of the society. Many, young generation's involved in deviant activities were influenced by modern abusive qualities due to the flexibility in the institutional norms and values in the society. It has become a serious threat to Sikkim's society that large numbers of new generation are rapidly sinking into the ocean of drug addiction and this vulnerability of social problem among the youths depict the lack of constant attention on proper institutional socialisation of individuals. Basically, those primary institutions of the society have been transformed into new structure and roles which turn as components of pushing and pulling towards the deviant means. However, there had been changes taking place in terms of development, the family has lost its original values for the process of socialisation of young and the role of media became important tool of exposure.

The problem of drugs, covered by the media on a regular basis, is a reflection of the product of complex societal conditions. Drugs are becoming common phenomena among the youths and drug addiction is state of psychological dependence on the substance. ${ }^{24}$ In family, parents are the role model for their child, as changes take place in social structure, the role of parents is also changing and directly or indirectly affecting their child. The influence of peers tends to increase as the influence of family decreases. ${ }^{25}$ Thus, 'social change is basic to the appearance of social problems. A change inevitably threatens strong interests, disrupts habits, creates distress, and result in the development of new social patterns. Social change generally focuses on conflict of values' ${ }^{26}$ This modern culture consequently reflects the "status frustration" 27 , because there is unequal access to opportunity, there is greater pressure on certain groups within social structure to deviate. There is constantly increasing of anomic situation in the society, which is leading to high risk of drug abuse due to inequality and disorganisation of families in the Sikkim's society. Cannabis (ganja), heroin and pharmaceutical drugs (cough syrups and N-10, Spasmoproxyvon, and Valium 10) are the most frequently abused drugs in the state of Sikkim.

\section{The rationale of Study:}

The study will focus on relationship between the changes in socio-economic status of families as significant factor of drug abuse among the youth in Sikkim. The role of traditional family in socialising the young highly depends on moral values which limits the other external influences on the children. ${ }^{28}$ Families can have mighty hands on shaping the attitudes of children, with the social norms and values, but today why are peer groups more influential among the children than families? Why is there a gap in relationship between parents and the children in contemporary society?

These are some of the gradually emerging problems in families and turning into disorganised institution directly affecting the psychological condition of children. The family issues are contributing factor for adolescents

21 Joshi H. G. 2004; “Sikkim Past and Present", pp. 70.

${ }^{22}$ Hurten Paul B. And Lesli Gerlad R. "The Sociology Of Social Problems", pp.8

${ }^{23}$ Singh Yogendra, 2009; "Modernization Of Indian Tradition", pp.194

${ }^{24}$ See Kaur Ravneet, "Drug Abuse: trends and Issues"

${ }^{25}$ Skinner et al. 1991

${ }^{26}$ Ibid pp. 556

${ }^{27}$ Haralambos M., 2002; pp. 416,417

${ }^{28}$ See "The Social Impact Of Drug Abuse", pp. 10 
to drug abuse. ${ }^{29}$ Parents are not only significant family members, siblings, uncles, aunts, cousins, and grandparents also have a significant role in shaping the attitude of adolescents. ${ }^{30}$ The increase in a number of drug abuse depicts the breakdown of traditional family values and social cohesion. Most of the teenagers usually do, breaking rules, starting arguments, showing negative attitudes and come home late at night are few changes in their personal behaviours which is the warning sign of drug abuse in contemporary society. Drug addiction generally refers to illegal drugs, although the social significance of alcohol, tobacco, and tranquillizer should be noted, and the concept of addiction suggested that dependent on something psychologically with grave consequences for the individual and society. Drug addiction is the bane of modern society, it was estimated that 185 million global consumers of illicit drug in the year of 2000 , by WHO and about $80 \%$ of the global deaths due to the illicit drug use are in men. ${ }^{31}$ It is not linked with the religion, caste or language and it is not due to the genetic problems but there is a serious problem in the structure and culture of society which in an epidemic of drug addiction. Drug addiction is not an individual problem but it affects the entire society as a whole and becomes a serious social problem in present society. Now the culture of society has become flexible due to the gradual changes in socioeconomic status and involvement of groups in leisure activities. According to R. K. Merton, deviance results not from 'pathological personalities' but from the culture and structure of society itself. ${ }^{32}$

\section{Analytical framework}

The analytical framework of the present study includes a discussion on research questions and the purpose of the study followed by the hypothesis and the research design.

\section{Research Questions:}

At present, the state of Sikkim has witnessed a large scale change in its socio-political and economic conditions over the years and this has had a debilitating impact on the life of the individuals. The macro level changes in the state have had its effect at the micro level of the individuals and the family, its values and world view. The following research questions are designed to arrive at clear picture of the presence of drug addiction and its threat in the study area.

1. What has been the impact of the changes in the outside world to the people of Sikkim?

2. Is drug abuse in Sikkim due to the ever-increasing cultural lag?

3. How have social changes affected the behaviour of individuals and thereby drug abuse?

4. Is there any relationship between drug abuse and the breakage of societal bonds and solidarity?

5. What is the relationship between drug abuse and the changing family structure in Sikkim?

\section{Aims and Objectives:}

On the basis of the above-mentioned research questions the specific aims and objectives of the study are as follows:

- To study the impact of social changes in the society and how it leads to drug abuse.

- To study the relationship between drug abuse and social support and social control in the society.

- To study the socio-economic status of drug addicts.

- To examine the relationship between drug abuse and institutions of the society.

\section{Study Area}

The study will be carried out in the 2 districts of the state of Sikkim the south and east district. In the South district Namchi and Jorethang are the study area and Singtam and Gangtok in East District of Sikkim. These places have been selected due to the growing problems of drug abuse.

\section{Methodology}

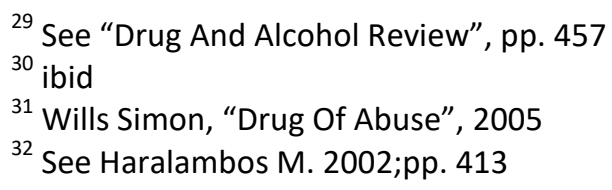


On basis of above objectives, this research will be based on both the secondary and primary sources of data. As part of field study, data will be collected by employing qualitative as well as quantitative methods; sample will be derived by using purposive and snowball technique. Primary data will be collected using structured and unstructured interview schedule among the drug users, illicit drug peddlers, teacher and parents of drug addicts as well as people who have knowledge on drug addiction as key informants. This kind of field research for the testing of hypothesis can give us appropriate data which may be helpful for drawing conclusions.

Focus group discussion among the inmates of rehabilitation centres will also be conducted to get a fully fledge opinion of the people who have been inflicted with drug abuse and in-depth interviews of people working in the field of drug control as well as parents of former as well as current drug addicts will also be done.

\section{The Profile of Respondents}

The composition of population constitutes both male and female. There are 117 respondents and effort was made to include important variables including gender, religion, age group, marital status, education qualification, occupation, rehab centres, addict and alcoholics. The male respondents were high than the female respondents as they were more willing to interact with the researcher. They had sound knowledge 'substance abuse' and some of them were encouraging and supportive. In all the places the respondents had witnessed the problem of substance abuse and root causes were different. At the household level, the males responded first than females and in case of male absence, they responded and interacted. The females were also engaged in business activities and had their own shops which have changed the economic status of women in the state. They are empowered in some parts of social life and they are not confined to the four walls of the house and household activities. However, this has had impact on the family and the familial relations. The problems are not solved but have evolved more in families and societies frequently.

Total of 117 individuals was interviewed and tried to look at the different perspectives of people from different background. Interviews were conducted with general public, drug users and alcoholics, and social workers. They expressed their knowledge of understanding the substance abuse in Sikkim which has facilitated this research.

\section{Gender Structure of Population}

The gender composition of respondents comprises of 89 males and 28 females. The male percentage is $76.06 \%$ and the female $23.93 \%$.

Table 1: Gender Structure of the Respondents.

\begin{tabular}{|l|c|l|}
\hline Gender & Numbers & Percentage \\
\hline Male & 89 & $76.06 \%$ \\
\hline Female & 28 & $23.93 \%$ \\
\hline Total No. Of Respondents & $\mathbf{1 1 7}$ & $\mathbf{1 0 0 \%}$ \\
\hline
\end{tabular}

Source: Field Data Jan.-Feb.2013.

\section{Religion}

There is a variation among the respondents with regards to the religion the practice. Among the 117 respondents, maximum are those who practice the Hindu religion and others follow Buddhism and Christianity. 71.79\% followed Hindu religion, 16.23\% followed Buddhist religion, and 11.96\% followed Christian religion. They celebrate the festivals and practices rituals of their own religions and the ritual are not maintained its originality as 
earlier times. The test of religion is becoming different today because of individualistic set of mind of the people. People are converting into other religion which has become the main factor for social disintegration in society.

Table 2: Religious Composition of the Respondents

\begin{tabular}{|l|c|c|c|l|}
\hline Religion & \multicolumn{2}{|l|}{ Male } & Total & Percentage \\
\hline Hindu & 61 & 23 & 84 & $71.79 \%$ \\
\hline Buddhist & 16 & 3 & 19 & $16.23 \%$ \\
\hline Christian & 12 & 2 & 14 & $11.96 \%$ \\
\hline Total & $\mathbf{8 9}$ & $\mathbf{2 8}$ & $\mathbf{1 1 7}$ & $\mathbf{1 0 0 \%}$ \\
\hline
\end{tabular}

Source: Field Data Jan.-Feb.2013.

\section{Age Structure}

The age of the respondents is varied. The youngest age of the respondents is 18 years and the oldest age is 66 years. The age group of 20-30 years are $47 \%$ highest, the age group of 30-40 years are $38.46 \%$, the age group of $40-50$ years are $5.98 \%$, the age group of below 20 years are $5.12 \%$, the age group of 50-60 years are $2.56 \%$, and the age group of 60 and above is $0.865 \%$ out of 117 respondents.

Table 3: Age Structure of the Respondents

\begin{tabular}{|l|c|c|c|l|}
\hline Age Group & Male & Female & Total & Percentage \\
\hline Below 20 Yrs. & 4 & 2 & 6 & $5.12 \%$ \\
\hline $20-30$ Yrs. & 42 & 13 & 55 & $47 \%$ \\
\hline $30-40$ Yrs. & 34 & 11 & 45 & $38.46 \%$ \\
\hline $40-50$ Yrs. & 5 & 2 & 7 & $5.98 \%$ \\
\hline $50-60$ Yrs. & 3 & 0 & 3 & $2.56 \%$ \\
\hline 60 and Above & 1 & 0 & 1 & $0.85 \%$ \\
\hline Total & $\mathbf{8 9}$ & $\mathbf{2 8}$ & $\mathbf{1 1 7}$ & $\mathbf{1 0 0 \%}$ \\
\hline
\end{tabular}

Source: Field Data Jan.-Feb.2013.

\section{The Marital Status}

The maximum numbers of respondents were unmarried or never married and married respondents were lesser in number. Maximum of them lived in a nuclear family structure and few were in joint family structured. The married respondents were $43.58 \%$ and the never married respondents were $56.41 \%$. This table shows the never married were higher than the married. 
Table 4: Marital Status of Respondents

\begin{tabular}{|l|c|c|c|c|}
\hline Marital Status & Male & Female & Total & Percentage \\
\hline Married & 38 & 13 & 51 & $43.58 \%$ \\
\hline Never Married & 51 & 15 & 66 & $56.41 \%$ \\
\hline Total & $\mathbf{8 9}$ & $\mathbf{2 8}$ & $\mathbf{1 1 7}$ & $\mathbf{1 0 0 \%}$ \\
\hline
\end{tabular}

Source: Field Data Jan.-Feb.2013.

\section{Education Qualification}

There is different education qualification of the respondents which varies from primary to post graduate level of both male and female. The education becomes important to Sikkim's people to get employments and people are doing higher studies, but however, there is also a problem of drop outs in Sikkim. Similarly, the educated unemployment is coming up as youth problem in Sikkim. The educated male respondents are highest in number than the female. There is $8.54 \%$ respondents were under primary education level, $17.94 \%$ were from high school level, $12.82 \%$ were from secondary education, $27.35 \%$ were from senior secondary, $25.64 \%$ were from graduate and $7.69 \%$ were from post graduate level. Up to primary level was the elderly people or mature respondents and very few were the young once, the highest number of respondents were under graduate and graduates $25.64 \%$.

Table 5: Education Qualification of Respondents

\begin{tabular}{|l|c|c|c|l|}
\hline Education & Male & \multicolumn{2}{|l|}{ Female } & Percentage \\
\hline Up-to Class V & 9 & 1 & 10 & $8.54 \%$ \\
\hline VI- VIII & 16 & 5 & 15 & $17.94 \%$ \\
\hline IX- X & 12 & 3 & 32 & $27.35 \%$ \\
\hline XI- XII & 22 & 10 & 30 & $25.64 \%$ \\
\hline Graduate & 24 & 6 & 9 & $7.69 \%$ \\
\hline Post-Graduate & 6 & 3 & $\mathbf{1 1 7}$ & $\mathbf{1 0 0 \%}$ \\
\hline Total & $\mathbf{8 9}$ & $\mathbf{2 8}$ & & \\
\hline
\end{tabular}

Source: Field Data Jan.-Feb.2013.

\footnotetext{
${ }^{33}$ The under graduates are also include in this.
} 


\section{Occupation}

The occupation of respondents also varies. Some are in government employment, private employment, selfemployment, students and unemployed, and this variation is also evident among the males and females. The employed respondent was high in number than unemployed which includes housewives, students and jobless people. The respondents from the occupation were higher in number than others. There was respondent from various occupation. $22.22 \%$ were employed in government services, $7.69 \%$ were employed in private services, $35.89 \%$ were self employed $13.67 \%$ were students, and $20.51 \%$ were unemployed.

Table 6: Occupation of Respondents

\begin{tabular}{|l|c|c|c|l|}
\hline Occupation & Male & \multicolumn{2}{|l|}{ Female } & Potal \\
\hline Govt. Employed & 22 & 4 & 9 & $26.22 \%$ \\
\hline Private Employed & 6 & 3 & 42 & $35.89 \%$ \\
\hline Self Employed & 34 & 9 & 16 & $13.67 \%$ \\
\hline Student & 10 & 6 & 24 & $20.51 \%$ \\
\hline Unemployed & 18 & 6 & $\mathbf{1 1 7}$ & $\mathbf{1 0 0 \%}$ \\
\hline Total & $\mathbf{8 9}$ & $\mathbf{2 8}$ & & \\
\hline
\end{tabular}

Source: Field Data Jan.-Feb.2013.

\section{Rehabilitation Centres}

The 38 people associated with substance abuse were interviewed during the fieldwork. People like drug users, alcoholics, counsellors and instructors of five rehabilitation centres were part of the study. In 32 Mile, Nimtar 'Sikkim Rehabilitation Centre' there was 21.05\% respondents including 7 male and 1 counsellors, 21.05\% 'Serenity Homes' in Gangtok, 13.15\% Jaagriti in Gangtok, 13.15\% 'Sanjeevani Rehabilitation Centre' in Namchi South Sikkim 'Drishya Rehab Centre', $21.05 \%$ in Aho village, East Sikkim, and $10.52 \%$ are from Jorthang and Singtam, they have never been in rehab centres.

Table 7: Rehabilitation Centres

\begin{tabular}{|l|c|c|c|c|c|l|l|}
\hline \multirow{2}{*}{ Rehab Centre } & \multicolumn{2}{|l|}{ Drug User } & Alcoholic & \multicolumn{2}{l|}{ Instructor } & \multirow{2}{*}{ Total } \\
\cline { 2 - 6 } & Male & Female & & Male & Female & & \\
\hline 32 Mile, Nimtar & 7 & 0 & 0 & 1 & 0 & 8 & $21.05 \%$ \\
\hline $\begin{array}{l}\text { Serenity, } \\
\text { Gangtok }\end{array}$ & 4 & 0 & 2 & 2 & 0 & 8 & $21.05 \%$ \\
\hline
\end{tabular}

\footnotetext{
${ }^{34}$ Including businessmen and businesswomen, drivers, social workers.
} 
IRA-International Journal of Management E' Social Sciences

\begin{tabular}{|l|c|c|c|c|c|c|c|}
\hline $\begin{array}{l}\text { Jaagriti, } \\
\text { Gangtok }\end{array}$ & 3 & 0 & 1 & 0 & 1 & 5 & $13.15 \%$ \\
\hline $\begin{array}{l}\text { Sanjeevani, } \\
\text { Namchi }\end{array}$ & 1 & 2 & 0 & 1 & 1 & 5 & $13.15 \%$ \\
\hline $\begin{array}{l}\text { Drishya, Aho } \\
\text { Village }\end{array}$ & 4 & 1 & 1 & 2 & 0 & 8 & $21.05 \%$ \\
\hline Others 35 & 4 & 0 & 0 & 0 & 0 & 4 & $10.52 \%$ \\
\hline Total & $\mathbf{2 3}$ & $\mathbf{3}$ & $\mathbf{4}$ & $\mathbf{6}$ & $\mathbf{2}$ & $\mathbf{3 8}$ & $\mathbf{1 0 0 \%}$ \\
\hline
\end{tabular}

Source: Field Data Jan.-Feb.2013.

Official Data of the Year 2011 under the SADA: 2006 Act.

The State Crime Branch office at Gangtok, East Sikkim, provided the official data on SADA: 2006, cases in the year 2011 and there was different figure of the cases according to each district of the state. The state comprises four districts and the East district has the highest number of cases recorded under the SADA: 2006, in the year 2011, followed by the South, West and North districts. The figure shows that $99(66.44 \%)$ cases were recorded in East district, followed by South district where $41(27.5 \%)$ cases were recorded throughout the year, the West district had $05(5.36 \%)$ cases recorded and the North district had $01(0.67 \%)$ cases recorded under the SADA: 2006. The figure has depicted that in North district of Sikkim has been very deeming in those cases as compare to the others. This district has lessened population and this is also far away from the mainstream societies and the impact of modernization and globalization is not effective in those areas. The social organisation of society called 'Zumsha' and that has significant role in maintaining the social coherence and lead to homogeneous society rather than heterogeneous society. This society has not let their traditional values from the society and consequently that have saved from the problems of substance abuse. The total number of cases recorded in the year 2011 was 149 in all over the state.

Table 8: SADA: 2006 Act, Year 2011.

\begin{tabular}{|l|c|c|c|c|l|}
\hline Districts & East & \multicolumn{2}{l|}{ West } & South & Total \\
\hline Jan. 2011 & 11 & 03 & 00 & 01 & $\mathbf{1 5}$ \\
\hline Feb. 2011 & 09 & 01 & 00 & 05 & $\mathbf{1 5}$ \\
\hline March 2011 & 08 & 00 & 00 & 12 & $\mathbf{2 0}$ \\
\hline April 2011 & 05 & 01 & 00 & 01 & $\mathbf{0 7}$ \\
\hline May 2011 & 07 & 00 & 00 & 02 & $\mathbf{0 9}$ \\
\hline June 2011 & 10 & 00 & 00 & 01 & $\mathbf{1 1}$ \\
\hline
\end{tabular}

\footnotetext{
${ }^{35}$ These four are also drug users but they are not part of any rehabilitation center.
} 
IRA-International Joumal of Management E゚ Social Sciences

\begin{tabular}{|l|c|l|l|l|l|}
\hline July 2011 & 06 & 00 & 01 & 06 & $\mathbf{1 3}$ \\
\hline Aug. 2011 & 12 & 03 & 00 & 05 & $\mathbf{2 0}$ \\
\hline Sep. 2011 & 09 & 00 & 00 & 01 & $\mathbf{1 0}$ \\
\hline Oct. 2011 & 06 & 00 & 00 & 02 & $\mathbf{0 8}$ \\
\hline Nov. 2011 & 11 & 00 & 00 & 02 & $\mathbf{1 3}$ \\
\hline Dec. 2011 & 05 & 00 & 00 & 03 & $\mathbf{0 8}$ \\
\hline Total 2011 & $\mathbf{9 9}$ & $\mathbf{0 8}$ & $\mathbf{0 1}$ & $\mathbf{4 1}$ & $\mathbf{1 4 9}$ \\
\hline
\end{tabular}

Source: State Crime Branch Head Office Gangtok, 2013.

Table 9: Four Districts Year 2011, SADA: 2006 Act.

\begin{tabular}{|l|l|l|}
\hline Districts & No. of Cases (2011) & Percentage \\
\hline East & 99 & $66.44 \%$ \\
\hline West & 08 & $5.36 \%$ \\
\hline North & 01 & $0.67 \%$ \\
\hline South & 41 & $27.51 \%$ \\
\hline Total & 149 & $100 \%$ \\
\hline
\end{tabular}

Source: State Crime Branch Head Office Gangtok, 2013.

Official Data of the Year 2012 under the SADA: 2006 Act.

The total number of cases recorded in the whole state was $121(100 \%)$ including the four districts of Sikkim. East district of Sikkim had highest number of cases have been recorded in the year 2012 as in the previous year and the figure was $72(59.50 \%)$. The second highest was South district which had 38 (31.40\%) cases recorded in the year 2012, followed by West district had been $08(6.61 \%)$ cases recorded and the North district has total number of 03 (2.47\%) cases registered. The number of cases under the SADA: 2006, of 2012 is slightly less than the number cases in the year 2011. However, it is disturbing that North district has shown an increase in the number of cases than the previous years. 
Table 10: Year 2012, SADA: 2006 Act.

\begin{tabular}{|c|c|c|c|c|c|}
\hline Districts & East & West & North & South & Total \\
\hline Jan 2012 & 06 & 01 & 00 & 06 & 13 \\
\hline Feb. 2012 & 05 & 01 & 00 & 00 & 06 \\
\hline March 2012 & 03 & 00 & 00 & 01 & 04 \\
\hline April 2012 & 06 & 00 & 00 & 04 & 10 \\
\hline May 2012 & 10 & 01 & 00 & 05 & 16 \\
\hline June 2012 & 14 & 00 & 01 & 04 & 19 \\
\hline July 2012 & 07 & 00 & 00 & 03 & 10 \\
\hline Aug. 2012 & 09 & 01 & 00 & 03 & 13 \\
\hline Sep. 2012 & 05 & 03 & 02 & 04 & 14 \\
\hline Oct. 2012 & 03 & 00 & 00 & 01 & 04 \\
\hline Nov. 2012 & 03 & 01 & 00 & 03 & 07 \\
\hline Dec. 2012 & 01 & 00 & 00 & 04 & 05 \\
\hline Total & 72 & 08 & 03 & 38 & 121 \\
\hline
\end{tabular}

Source: State Crime Branch Head Office Gangtok, 2013.

Table 11: Four Districts in the Year 2012, SADA: 2006 Act.

\begin{tabular}{|l|c|c|}
\hline Districts & $\begin{array}{l}\text { No. of Cases } \\
(2012)\end{array}$ & Percentage \\
\hline East & 72 & $59.50 \%$ \\
\hline West & 08 & $6.61 \%$ \\
\hline North & 03 & $2.47 \%$ \\
\hline South & 38 & $31.40 \%$ \\
\hline Total & 121 & $100 \%$ \\
\hline
\end{tabular}

Source: State Crime Branch Head Office Gangtok, 2013. 


\section{Official Data of Jan-Feb.2013 under the SADA: 2006 Act.}

There were few cases under the SADA 2006 registered from the districts of Sikkim and the month of January 2013 East district have been highest number of cases 04, South had 01 cases, and other had nil case. The month of February there had total 06 cases, out of that 05 cases have been registered in East district and 01 in West district of Sikkim and other districts have nil cases.

Table 12 Four Districts Year 2013, SADA: 2006 Act.

\begin{tabular}{|l|c|c|c|c|c|}
\hline \multicolumn{1}{|c|}{ Districts } & East & West & North & South & Total \\
\hline Jan. 2013 & 04 & 00 & 00 & 01 & $\mathbf{0 5}$ \\
\hline Feb. 2013 & 05 & 01 & 00 & 00 & $\mathbf{0 6}$ \\
\hline
\end{tabular}

Source: State Crime Branch Head Office Gangtok, 2013.

These data show that the cases of substance abuse in Sikkim have become a concern to the society and the state. The experiences of the respondents show that the people of different walks of life has been affected by substance abuse and elements of modernity and the anomie created by the drastic changes in the cultural system of the society is also responsible for the present scenario of substance abuse in the state.

\section{Major Findings}

90 per cent of the males in the sample have reported having indulged in drinking alcohol sometime in their life and cigarette smoking was very common among them. Even the females reported to drinking beer at certain points in time. Substance use and abuse among the students were found to be common. Respondent in the sample has reported to high use of substances being common in the colleges and students. No awareness programme has been conducted to make the students aware of their vulnerable conditions till now.

Today in Sikkim large numbers of families are living as nuclear family where both the parent is working. That they are spending very less time at home or with their children and this is causing frustration and emotional detachment among them. The gap between parent and child has increased today. Even the relation with the close kinsmen and relatives has become distant and individuals have no time. That is how their busy life leading to drugs and alcoholism.

In Sikkim urbanization is rapidly emerging which is changing the cultural norms and values. Large numbers of people are moving to the urban areas and there has been exposure to different cultures. They have broken the traditional values of the family which has led to the family bounding to decline. There has been stress in the husband and wife relations, divorce has become a new trend. Making girl friends and boyfriends among the young teenagers has become a culture, celebrating birthday, late night parties with alcohol and drugs, enjoyment in disco etc. Money or materials have become the means to express sentiments and emotions even to children by parents and that has led to change in individual behaviours in society.

In the state there are emerging industries as products of modern developments. These are proving to be negative because it has increased the availability and accessibility of drugs and alcohol, which has forced many young people in society to indulge in alcoholism and drug addiction. It has become more common with the emerging urban areas and large number of communication and transportation advancement in the state. Communal harmony is lost in society due to selfishness among the individuals and family disorganization is also increasing which have impacted in the changing behaviour of young peoples in society. Though the social customs of the society accept the use and consumption of alcohol drugs are not accepted. The young people are, however, indulging in both. The age group of 18-30 years is the largest group to indulge in the abuse of both alcohol and drugs. 
There are few NGOs working in the field of substance abuse and they are working only in rehabilitating those who are involved in substance abuse. They do not have well-trained coordinators and counsellors. They do not have any programmes for raising awareness among the people and the students who are the most vulnerable group in the state. The government is funding the NGOs for controlling the menace of substance abuse in the state but they do not have any holistic programme on their own.

Drugs and alcohol in the state of Sikkim are easily available and is brought into the state from the neighbouring areas. The availability of drugs has led many to abuse it. Lack of employment opportunities and the motivation to earn money and quickly has forced many to peddle drugs into the state thereby making the availability more. There are too many bars and wine shops which make alcohol easily available to everybody.

The general public thinks that alcohol consumption is better than drug abuse. At the societal level these drug addicts are not trusted by the people. They are seen as anti-social elements. They are perceived to be stealing things from places and not contributing the society. The drug addicts are discriminated and stigmatised and are not helped if they look for any help. This in turn develops an attitude of distrust among the drug addicts against the society as well. Drug abusers are stigmatised and discriminated in the society. Drug abusers and addicts are treated as criminals and think that they should be severely punished. People are not aware of the fact that substance abuse can be treated by medical intervention.

\section{Conclusion}

Substance abuse among the young people has become a genuine social problem in Sikkim. The problem of Substance abuse is increasing everyday in Sikkim as in the other part of world and which indicates the increasing social crisis in the society. There are much more changes taking place in the society and substance abuse among the young people also become common in the state. The socio-economic development has emerged after the merger with India which led to the several changes in the society. In the growing of urbanization in state has led large number of people settlings and establishments of new offices, bank system and jobs etc. the economical progress of state due to employment and other developmental schemes has led people busy in their professions life has also led to change in the family and social life. The agriculture becomes secondary source and education and employment became primary source of earning among the people of Sikkim today. There are families where both husband and wife are employed in offices and other institution has been improving the economic situation of family.

The people today have lessened their engagement in the familial and societal level which has lessened the family bounding. The young people have more prone to indulge into substance abuse in society and especially their parents are employed. There is declining of family values of love and care and also the coordination between parent and children have been lost. They young people are meeting friends in bars, hotels, discos, clubs, in mobiles and internet etc are the modern means and they are gradually stepping towards the alcoholism and drug abuse. There are increasing connections among the young drug users due to their mobiles and internet facilities and the young teens are involving due to the encouragement from their elderly drug user friends in the locality. The young people are coping the fashion or trends of western culture and basically the follow the models, actors, and singers. Due advancement in mass media young people are more influenced by the movies and TV serials and they start making girlfriend or boyfriend in schools or colleges if the relation breaks they are prone to indulge into alcoholism, and drug addiction.

Emergence of pharmacies and other industries has brought drastic changes in Sikkim in terms of market, transport and communication as well as many youths getting jobs also. The people have become more achievement driven and the economic accessibility of young people has gained the decision making authority. The establishment of such industries has increased the availability of pharmaceutical drugs and alcohol in the state and easily the young people are stepping into substance abuse in the society. More young people in the state are indulging into drug addiction because they are failure in socialization due to their family problems and their single parent system. Alcohol in birthday parties or any social gatherings is encouraging factor for young and smoking ganja with friends is also common to young people in Sikkim, public toilets, taxi stand are the common areas for drugs use and drugs 
peddling. Ganja is common drug of abuse among school students or teenagers and youths and they are favouring pharmaceutical drugs with specific reasons of good kick than alcohol and easily non-recognisable like alcohol.

The East Districts and South Districts have largely faced the problems of substance abuse among the young. These areas are highly urbanised and cosmopolite's culture or trends among the people are very high and basically the young people are influenced by these trends of life in these areas. Today family bounding is not strong as in earlier day and it has gone change over the years of time. The people most probably stay away from the home due to their tight schedule or service they acquired in government and private sectors. The husband, wife and children remain separately in today world is distinctly visible in Sikkim in terms of education, services and personal interest. To get rid of any kind of stresses or tension people go for alcohol and drugs. Here people are entertainment lover due to tourist culture influenced many young to do funs they take drugs and consume alcohol. That is why many young people are hooked into drugs for seeking enjoyment. In the neighbours do not bother if their neighbour's child is drug addict but only bother about their own child would not become drug addict. There is change in the people behaviours and the community sentiments today has deemed today in urban areas of Sikkim.

The society of North District of Sikkim is highly followed the traditional values and norms in the society which has led their continuation in the community sentiments as earlier days. The ratio of substance abuse in this area has none and they still have joint family system and they have high family bounding. The people have their traditional values guiding their social lives and especially the children have great ties with families and their parents. They have traditional meditational practices and they are not linked with the mainstream society. They have unique social lives in the society and their local governance help to maintain peace in the society. This is how in North Sikkim their traditional values have been increasing family ties and social community bounding in the society and controlling from dangerous substance abuse. The people of society neighbour also do cares and guide the children of locality.

But in few years ago government has started allowing the private companies to take over the land for hydro power projects which has largely effected the social and physical environments of North Sikkim. That has increased out numbers of outsiders into the restricted lands has led to change in the lives of local people.

The East and the South Sikkim has close connection with West Bengal and the 31A National Highway has also led to easy connectivity of the lands has increased the risk of substance abuse in these areas. The areas of Jorthang has witnessed many people from the West Bengal has caught in the cases of drug trafficking. Rangpo in the same way, even Singtam most of the drug peddlers are due to their link with outsiders. The changing social trends in society have led to the trends of drugs using among the young people in the state and the intravenous drugs users are also common in these areas. Most of the young drug users ignored the health and economic consequences in their lives.

Those affected families have lost faith on their child who has involved in drug addiction and they didn't support or cares and today the rehabilitation of state is helping on its way but their failure in treatment due to those families that is why so many relapsed people or becoming more chronic. Most of the peddlers have built their relation during the rehabilitation and after getting out they start business again in same way. The situation becoming worst day by day due to the failure in legal system and some police officials are taking bribe in the check post from the peddlers. The peddlers are selling large amount of the pharmaceutical drugs and the number of drug users has increased in state.

Urbanism and industrial emerging in Sikkim have changed the social structure and culture of the society. The greater assimilation of different community people in these urban areas has making heterogeneity due to over population with various backgrounds of people and there is not recognisable that neighbour to your flat or apartments have drug peddler. And family has largely disorganised breaking of relation and distanced with close kinsmen and relatives due to their jobs or services they engaged most of the time and it is due to breaking of traditional values and the young people are not given proper cares and guidance. Some families have illiterate parents and they treated their children with ignorance and there is clash between parent and children also led to frustration and depression ultimately to substance abuse. Due to change in the family there has been changing in behaviour of the child as well and that peer pressure also one of the influenced for the substance abuse in early ages. 
The people mentality here to have changed they become more selfish in nature and political leaders are after the huge profit for them self is becoming part of Sikkimese social life.

Family and other social organization have failed to control the problem of substance abuse in Sikkim. There are more complex choices among the people living in society due to various changes taking place and emerging availability in the state. The technology also to the great extent contributes to building social relations unstable in society and there are gradually changing the behaviour of people and rapidly among the young people in society. There is increasing gap between the trends of culture of contemporary Sikkimese society and traditional values have led to the emergence of serious social issues like substance abuse among the young people in the society.

The research had proven true that social changes in society have led to the problem of substance abuse in the Sikkim.

\section{References:}

[1]. Ahuja Ram, 1997; 'Social Problems in India', Rawat Publication, New Delhi.

[2]. Das B. S. 2002; "The Sikkim Saga” Vikas Publishing House Pvt. Ltd.

[3]. Garcia victor and Gonzalez, 2011; 'Participatory Research Challenges in Drug Abuse Studies among Transnational Mexican Migrants', The Open Anthropology Journal, pp 3-11. Murthy Pratima, et.al. 'Substance use and addiction research in India'. (www.indianjpsychiatry.org on March 28,2011)

[4]. Horton Paul B. and Leslie Gerald R., 1995; "The Sociology of Social Problems", Appleton-Century-Croft, Inc. New York.

[5]. Jiloha R. C. and Sain B., 1992; "From Drug To Dragon”, Mital Publication.

[6]. Joshi H. G., 2004; "Sikkim: Past And Present", A Mital Publication.

[7]. Laidler K.Joe and Pianpiano Joe, 'Understanding Local Synthetic Drug Trends in the Global Context and Implications for Treatment: the Case study of Hong Kong.

[8]. Lama Mahendra P., 2001; 'Sikkim Human development Report 2001', Social Science Press, Delhi, India.

[9]. Lee Walter V. and Huey Chrystal M., 2007; 'From The Darkness Of Addiction To The Dawn Of Recovery A Practical Guide For The Family Afflicted With Alcohol And Drug Addiction', Author House Publication.

[10]. Mehta Prashant, 2011; 'Evaluative Trends of Illicit Drug Uses In India and Analysis of India and International Laws of Prohibition of Drugs of Abuse.

[11]. O'Farrell Timothy J. and Stewart William Fals, 2006; 'Behavioral Couples Therapy for Alcoholism and Drug Abuse', The Guilford Press New York London.

[12]. Sengupta Nirmalananda, 1985; "State Government And Politics In Sikkim" Sterling Publishers Pvt. Ltd.

[13]. Sharma Rajendra Kumar, 2004; "Urban Sociology", Atlantic Publishers and Distributors.

[14]. Shiner Michael, 2009; "Drug Use And Social Change", Palgrave Macmillan Publication.

[15]. Singh Yogendra, 2009; Modernization of Indian Tradition, Rawat Publications.

[16]. Srivastava Vinay Kumar, 2004; "Methodology And Fieldwork", Oxford University Press, New Delhi.

[17]. Sundas Binu, 2011; "HIV and AIDS in Darjeeling", Concept Publishing Company Pvt. Ltd.

[18]. Thomb Denis L. 2006; 'Introduction to Addictive Behaviors Third Edition', The Guilford Press New York London.

[19]. Thomas Yonette F., Richardson Douglas, and Cheug Ivan, 2009; 'Geography and Drug Addiction', Springer Publication.

[20]. Uggen Christopher and Thompson Melissa, 2003; 'The Socioeconomic Determinants of Ill-Gotten Gains: WithinPerson Changes in Drug Use and Illegal Earnings', American Journal of Sociology.

[21]. World Drug Report 2012.

[22]. Young Pauline V. 2009; "Scientific Social Surveys and Research”, PHI Learning Pvt. Ltd. New Delhi. 